\title{
Utilization of Locally Available Raw Clay for Property Enhancement of Polymer Composite by Clay Particle Size Control
}

\author{
M.A.S.R. Saadi ${ }^{1}$ and M.A. Islam ${ }^{2}$
}

\begin{abstract}
Composites are wonderful materials in the sense of good combination of various engineering properties. The past decade has seen a renewed interest in developing more efficient low cost materials. In this regard, polymer composites have gained much more attention because of their light weight, low cost, ease of fabrication, corrosion resistance, good wear property and so on. In this regard, large quantities of clay minerals (also other micronsized mineral powders) are widely used as reinforcements for polymer matrix composites. This paper concentrates on the effects of particle size of locally available raw clay (bentonite type) on the tensile and thermal stability of polyester matrix polymer composites. At first, composites were developed and then tensile tests were conducted using universal testing machine (UTM, Model: Instron 3369). Thermo-gravimetric analysis (TGA) was also performed on the developed composites materials in order to observe the thermal degradation behaviours of the composites. Experimental results revealed that locally available clay might be a potential source of a very low cost reinforcement material for polymeric materials. However, for better tensile strength and thermal stability raw clay needs to be ground to a finer level.
\end{abstract}

Index Terms - Raw Clay, Polymer Composite, Reinforcement, Particle Size, Thermal Stability.

\section{INTRODUCTION}

Starting from the Toyota Research Group first polymerclay nano-composite, the improvement of properties of these new classes of materials was intended for structural applications. Polymer clay composites can be classified as macro-composites, micro-composites and nano-composites according to fillers sizes [1]-[2]. The applications of clay composites are in very wide fields as automotive, general and industrial applications like packaging, aerospace, electronics industries, mobile phones and fuel tanks [3]-[5]. There is an increased interest in mineral clay based composites due to its layered structure, large surface area and high aspect ratio of the mineral clay. In recent years, the use of organo-clays as precursors to composite formation has been extended to polymer systems including epoxy, vinylester, polyurethane, polyamides and polyesters [6]. Polyesters offer ease of handling, low cost, dimensional stability as well as good mechanical, chemical-resistance and electrical properties [7]-[9].

Bentonite group minerals show a colloidal structure in water, due to their internal structure and small particle size.

\footnotetext{
${ }^{1}$ Graduate student, Department of Materials and Metallurgical Engineering, Bangladesh University of Engineering and Technology (BUET), Dhaka-1000, Bangladesh.

2 Professor, Department of Materials and Metallurgical Engineering, Bangladesh University of Engineering and Technology (BUET), Dhaka-1000, Bangladesh,
}

They have a large adsorption capacity for polymer compounds due to their unique crystal structure [10]-[12]. Using montmorillonite, the matrix polymer is expected to display increased tensile strength and thermal stability, characteristic that makes it very useful in aerospace and automotive industry, fuel cells, food packaging, relatively high temperature application etc. In general, finer particle sizes are required to achieve high performance of the composites. Therefore, the effect of particle size on the properties of particle reinforced composites is particularly interesting research topic. It is often observed that there is a critical level of particle fineness that leads to an increase in tensile properties and thermal stability.

The aim of this work is to study the possibility of utilization of locally available clay as reinforcement materials in producing low cost polymer composites for making various engineering components.

\section{EXPERIMENTAL WORK}

\subsection{Materials}

In this experiment, unsaturated polyester resin was used as matrix material and locally available clay from Chuadanga region in Bangladesh was used as the reinforcement, Fig.1. The polyester resin was procured from the local market, whereas raw clay was collected directly from the source.

The lump of clay contains various coarse rocky particles. In order to separate them from the clay particles, the collected clay lumps were dissolved in water and a very thin clay slurry was made. This slurry was then vigorously stirred and settled for a while. This allowed the coarse particles to be settled down at the bottom of the container and from the top, the clay containing water was taken out in another container, where it was allowed to settle for a long time. Then clear water was removed from the muddy clay. This muddy clay was then dried at $110 \mathrm{oC}$ and ground for different time periods as 5,10 and 15 hours in a ball mill.

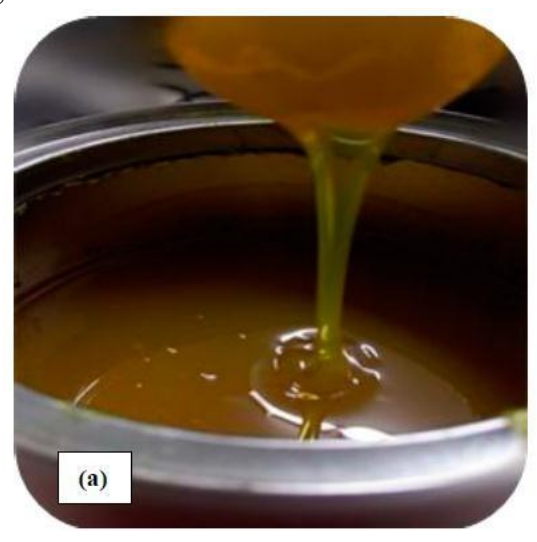



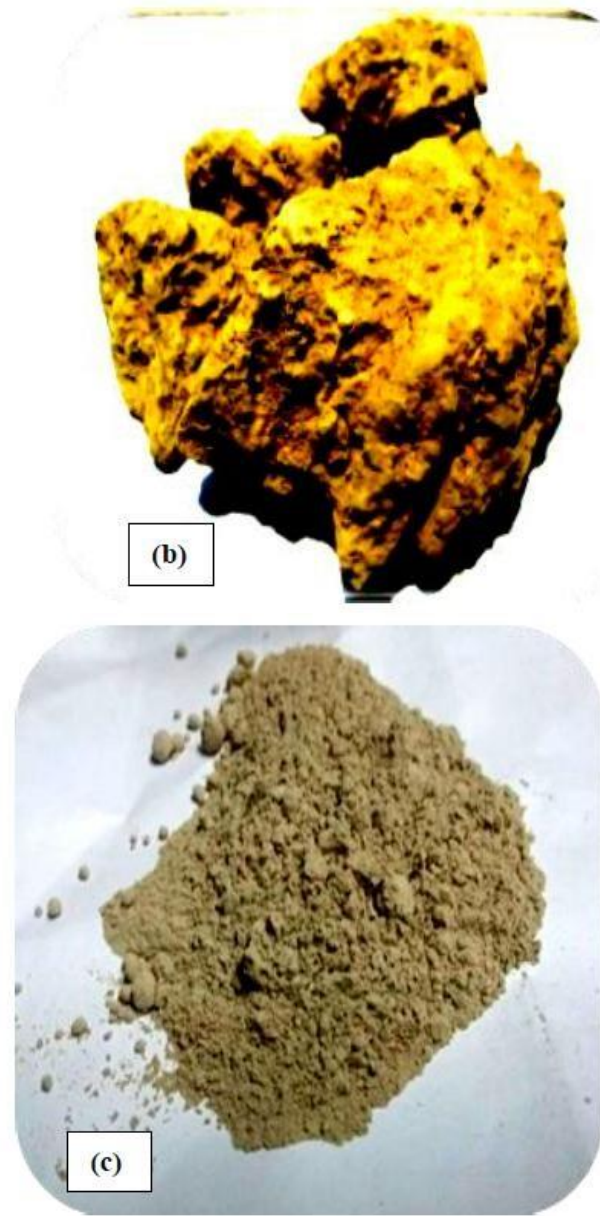

Fig. 1 Photographs showing (a) polyester resin, (b) clay lump and (c) ground clay.
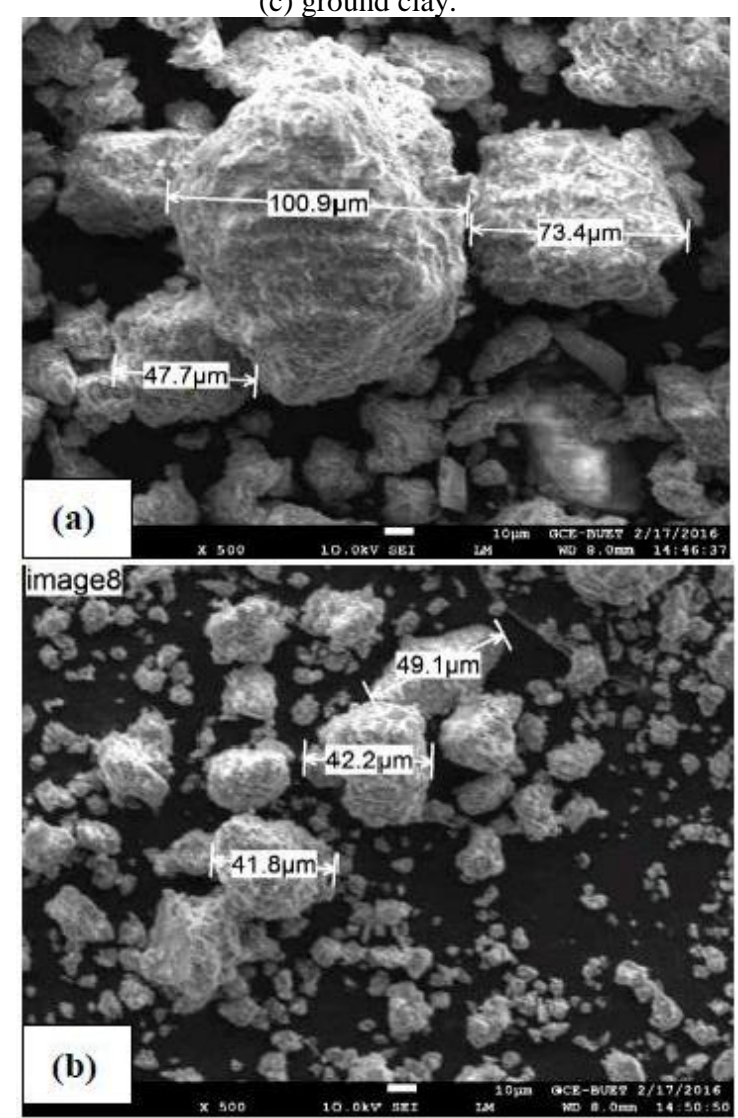
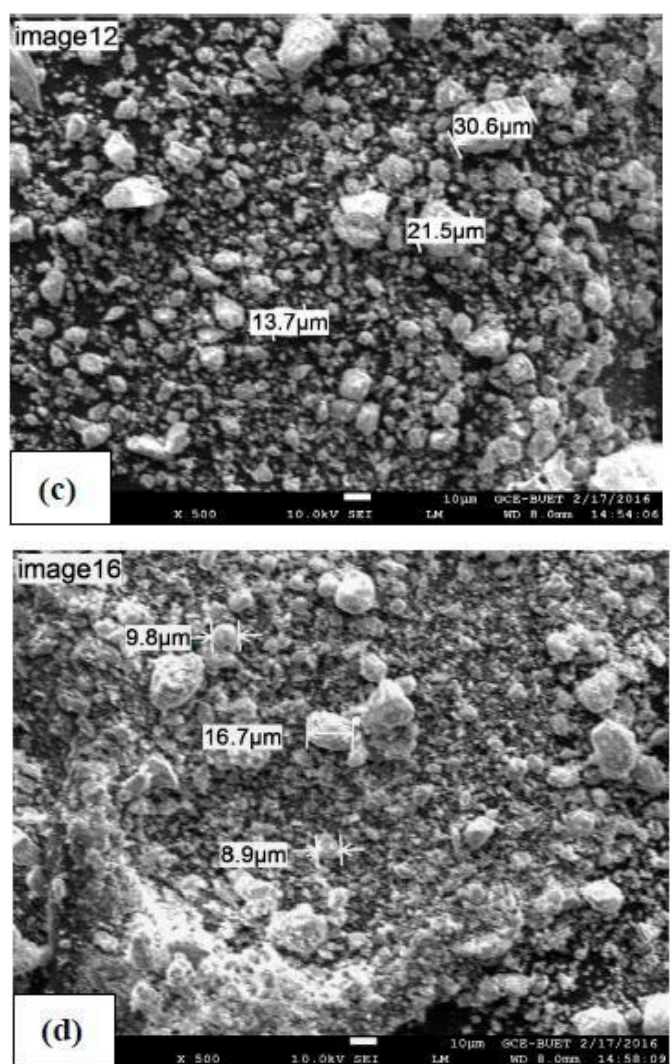

Fig. 2 Photographs showing clay particle sizes under various conditions (a) as received condition and after (b) 5 hours, (c) 10 hours and (d) 15 hours of grinding.

The average particle sizes of the clay particles are presented in Table 1.

TABLE I

AVERAGE ClAY PARTICLE SIZES

\begin{tabular}{|c|c|}
\hline Grinding Time (Hours) & Average Particle Size $(\boldsymbol{\mu m})$ \\
\hline As Received & 74 \\
\hline 5 & 44.3 \\
\hline 10 & 21.9 \\
\hline 15 & 11.8 \\
\hline
\end{tabular}

\subsection{Development of Composites}

Unsaturated polyester resin was used as matrix and methyl ethyl ketone peroxide (MEKP)] was used as hardener. The composite samples were prepared using hand layup method, which is a simple technique for composite production, by mixing the resin with clay particles in a container. The mixing step was performed very slowly to avoid the formation of bubbles followed by hardener addition and well mixing again. This mixture was then degassed by vacuum process (Fig.3) and finally poured into the mould for preferred composite.

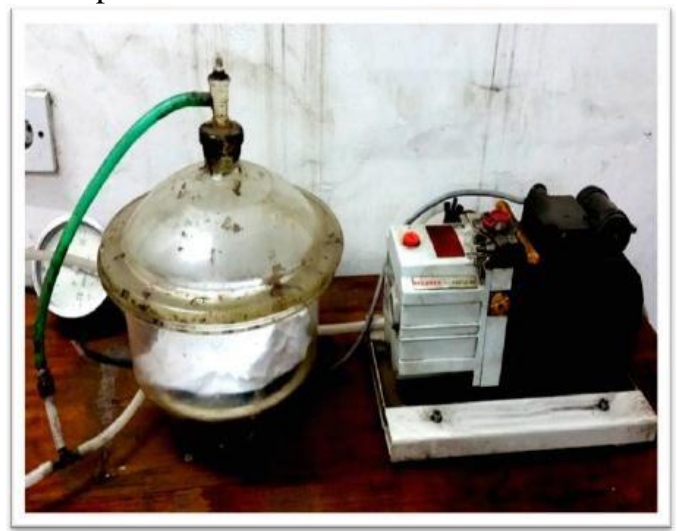

Fig. 3 Vacuum degassing for resin clay particle mixture. 


\subsection{Tensile Test}

Tensile test specimens were prepared from the developed composites and pure polymer casting according to standard specification. Then tensile tests were carried out in a universal testing machine of model Instron 3369 at a crosshead speed of $2 \mathrm{~mm} / \mathrm{min}$ according to ASTM D 638-01. Throughout the whole tensile test, the test specimen gauge length was kept $32 \mathrm{~mm}$ and the width was kept $6 \mathrm{~mm}$. For each composite, minimum three samples were tested.

\subsection{Thermo-Gravimetric Analysis}

Thermo-gravimetric analysis of pure polyester and composites were performed to determine the thermal stability of the composites. For each type of composites, 3 samples were tested.

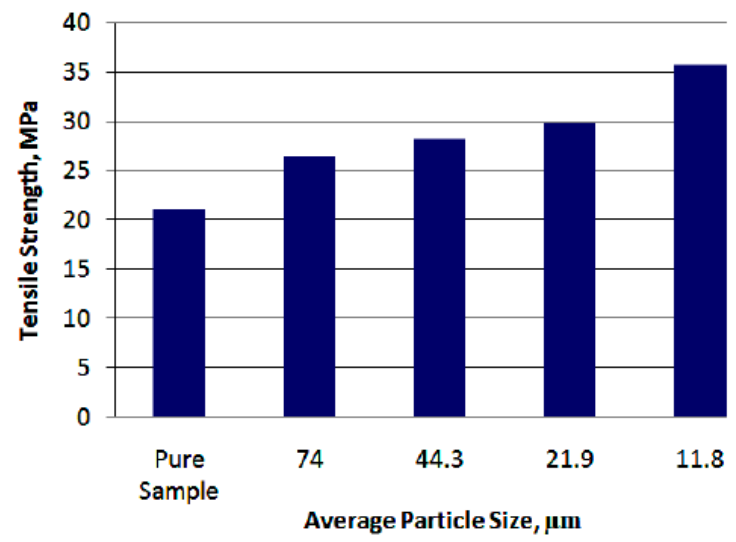

Fig. 4 Variation of tensile strength of the developed composites

\section{RESULTS ANDDISCUSSION}

The tensile strengths are compared in Fig.4. It can be seen that the tensile strength of the polymer composites increased with clay particle addition which have been improved gradually with the fineness of the clay particle sizes. Generally, the filler particles tie polymer chain bundles together by filling interstitial voids, thereby restricting molecular movement or slippage on application of tensile force [13]. At the same time, the filler particles assist in distributing any induced stress more equitably [14]. The overall internal changes are favoured by finer particle reinforcement. Therefore, with finer size of filler clay particles, tensile strength gradually increased.

Larger particles have smaller surface area, which also results in poor bonding of the filler and the matrix [15]. The poor adhesion between the hydrophilic clay fillers and hydrophobic polyester matrix is another reason. As a result, the stress transfer between the particles and matrix was very low [16]. However, with the decrease in particle size, the properties improve which indicates that finer particles result in better adhesion and stress transfer.

Thermo-gravimetric analysis was done in order to find out the thermal stability of the developed composites. In this study, all composite samples were heated to an identical temperature $650^{\circ} \mathrm{C}$. The test results were obtained as TGA curves showing both the \%weight loss and derivative weight change, Figs.5-7 and the detail results are presented in Table 2. All the TGA curves obtained are one-stage decomposition curves and therefore, can be used to define the stability limit of the samples.
TABLE II

EFFECTS OF ClAy PARITLE SIZES ONTHE DEGRADATION TEMPERATURES OF COMPOSITES

\begin{tabular}{|c|c|}
\hline Sample & Degradation Temperature $\left({ }^{\circ} \mathrm{C}\right)$ \\
\hline Pure Sample & 214.24 \\
\hline $74 \mu \mathrm{m}$ Composite & 237.94 \\
\hline $44.3 \mu \mathrm{m}$ Composite & 239.49 \\
\hline $21.9 \mu \mathrm{m}$ Composite & 251.90 \\
\hline $11.8 \mu \mathrm{m}$ Composite & 254.23 \\
\hline
\end{tabular}

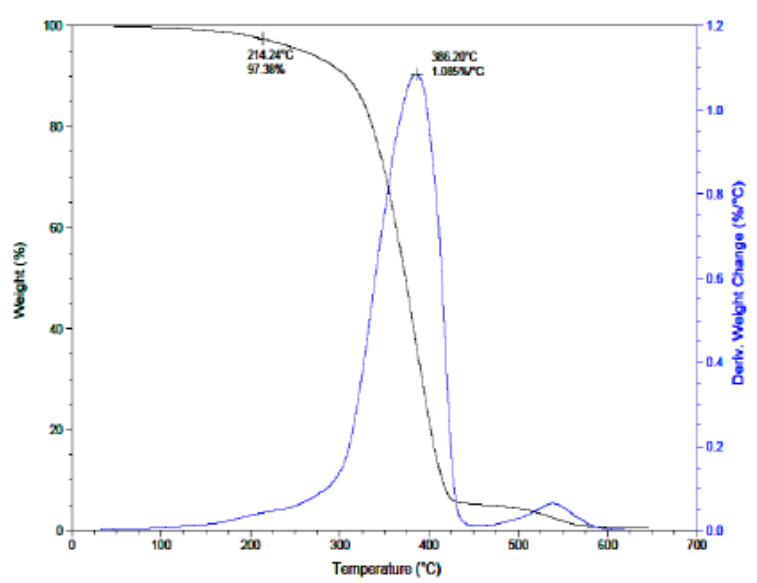

Fig. 5 Thermo-gravimetric analysis curves for pure polyester.

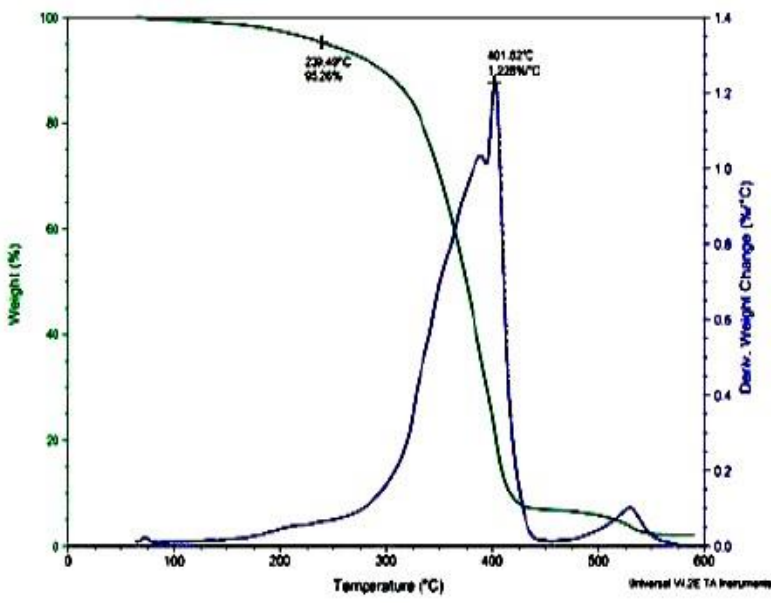

Fig. 6 Thermo-gravimetric analysis curves for composite with $44.3 \mathrm{~m}$ clay particles.

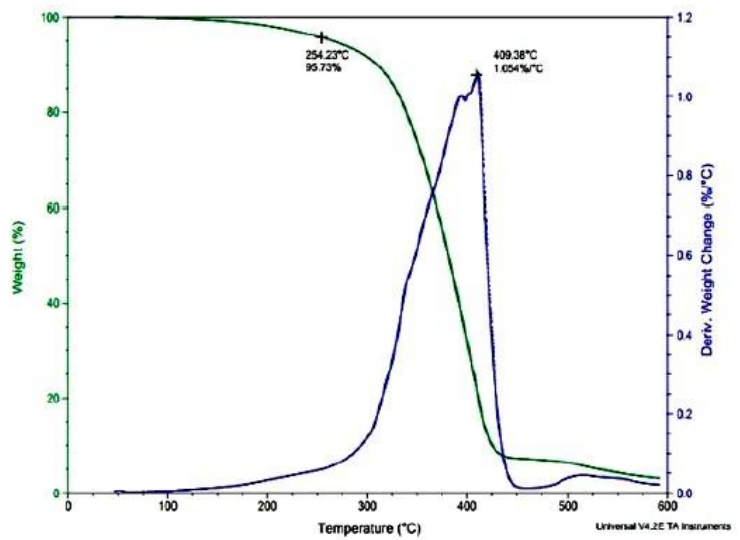

Fig. 7. Thermo-gravimetric analysis curves for composite with $11.8 \mu \mathrm{m}$ clay particles.

From thermal degradation temperature presented in Table 2 , it is clearly revealed that thermal stability for composites increased gradually with decrease in clay particle sizes. With the decrease in particle size, clay was more uniformly distributed around the polymeric molecules. Moreover, finer clay particles could fill theintermolecular and/or gas pockets 
in much more better way. As clay is a ceramic materials with high level of melting temperature, fine clay particles can build a potential barrier around polymeric materials and protect them in a better way. So, with decrease in clay particle sizes, the developed composites gradually became more thermally stable. This has also been mentioned by many investigators [17]-[20]. Zong et al also mentioned that nano clay particles increase the thermal stability along with its resistance to flame.

\section{CONCLUSION}

In this paper, the effects of particle size on tensile strength and thermal degradation behaviours of locally available raw clay particle reinforced polyester matrix polymer composites have been studied. The reduction in particle size showed an interesting property change. After this experimental study, it has been clearly revealed that for mechanical property enhancement and better thermal stability of polymeric materials the locally available raw clay might be a potential source for cheaper reinforcement materials. However, for better results, the raw clay needs to be separated from unwanted materials and ground to get finer clay particles.

\section{ACKNOWLEDGMENT}

The authors express their heartiest gratitude to Bangladesh University of Engineering and Technology (BUET) for providing necessary fund and research facilities to conduct this research work. This research results might reduce the dependency of imported nano clay particles for research purposes as well as in industrial production processes for making various low cost engineering items, especially for construction applications.

\section{REFERENCES}

[1] Chandra, Arup K., and Vivek Bhandari. "Nanocomposites for tyre applications." Advances in elastomers II. Springer Berlin Heidelberg, 2013. 183-203.. http://dx.doi.org/10.1007/978-3-642-20928-4_6

[2] Ataiwi, A. H., \& Abdul-Hamead, A. A. (2012). Preparing polyesterbentonite clay nano composite and study some of its mechanical properties. Emirates J Eng Res, 17, 57-61.

[3] Sanchez, C., Belleville, P., Popall, M., \& Nicole, L. (2011). Applications of advanced hybrid organic-inorganic nanomaterials: from laboratory to market.Chemical Society Reviews, 40(2), 696-753.. http://dx.doi.org/10.1002/1439-2054(20000601)279:1<1::AID-MAM E1>3.0.CO;2-Q

[4] Zanetti M., Lomakin S. \& Camino G., "Macromol. Eng.", Vol.279, 1-9 (2000).

[5] Park D.Y., Song R. Y., Yoo Y. and Myung N. V., "Electrochemical and Solid-State Letters", Vol. 8, No.2, 2005.

[6] Kotal, M., \& Bhowmick, A. K. (2015). Polymer nanocomposites from modified clays: Recent advances and challenges. Progress in Polymer Science, 51, 127-187.

http://dx.doi.org/10.1016/j.progpolymsci.2015.10.001

[7] Murphy, J. (1998). The reinforced plastics handbook. Elsevier.

[8] Odom, I. E. (1984). Smectite clay minerals: properties and uses.Philosophical Transactions of the Royal Society of London A Mathematical, Physical and Engineering Sciences, 311(1517), 391-409. http://dx.doi.org/10.1098/rsta.1984.0036

[9] Hassun, S.k. , (1990)" Visco relaxation study of polystyrene solutions in different solutions by ultrasonic", act a polymeric Journal, 41, 8.

[10] İş̧̧i, S., Ünlü, C. H., Atici, O., \& Güngör, N. (2006). Rheology and structure of aqueous bentonite-polyvinyl alcohol dispersions. Bulletin of Materials Science, 29(5), 449-456.

[11] Bledzki, A. K., \& Gassan, J. (1999). Composites reinforced with cellulose based fibres. Progress in polymer science, 24(2), 221-274. http://dx.doi.org/10.1016/S0079-6700(98)00018-5
[12] Yasye, K.; Katahira, S.; Yoshikawa, M.; Fujimoto, K. In situe polymerization route to nylon 6-clay nanocomposites. In Polymer-Clay Nanocomposites; Pinnavaia, T. J., Beall, G. W., Eds.; John Wiley and Sons: Chicester, 2000; pp 111.

[13] Ferrigno, T. H. (1987). Principles of filler selection and use (pp. 8-62). Van Nostrand Reinhold: New York, NY, USA.

[14] Aruniit, A., Kers, J., Tall, K. Influence of filler proportion on mechanical and physical properties of particulate composite. Agronomy Research, 2011, 5, 23-29.

[15] Fu, S. Y., Feng, X. Q., Lauke, B., \& Mai, Y. W. (2008). Effects of particle size, particle/matrix interface adhesion and particle loading on mechanical properties of particulate-polymer composites. Composites Part B: Engineering, 39(6), 933-961. http://dx.doi.org/10.1016/j.compositesb.2008.01.002

[16] Maji, P. K., Guchhait, P. K., \& Bhowmick, A. K. (2009). Effect of nanoclays on physico-mechanical properties and adhesion of polyester-based polyurethane nanocomposites: structure-property correlations. Journal of materials science, 44(21), 5861-5871. http://dx.doi.org/10.1007/s10853-009-3827-7

[17] H.R.R. Nafchi1, M. Abdouss, S.K. Najafi1, R.M. Gargari and M. Mazhar, Effects of Nano-Clay Particles and Oxidized Polypropylene Polymers on Improvement of the Thermal Properties of Wood Plastic Composite", Maderas. Ciencia y tecnología 17(1): 45 - 54, 2015.

[18] R. Zong, Y. Hu, N. Liu, S.Wang and G. Liao, "Evaluation of the Thermal Degradation of PC/ABS/Montmorillonite Nanocomposites", Polymers for Advanced Technologies, 2005; 16: 725-731. http://dx.doi.org/10.1002/pat.651

[19] Hashim, J., Looney, L., \& Hashmi, M. S. J. (1999). Metal matrix composites: production by the stir casting method. Journal of Materials Processing Technology, 92, 1-7. http://dx.doi.org/10.1016/S0924-0136(99)00118-1

[20] Curtin, W. A., \& Scher, H. (1990). Brittle fracture in disordered materials: a spring network model. Journal of Materials Research, 5(03), 535-553.

http://dx.doi.org/10.1557/JMR.1990.0535 